ASTHMA

\title{
The Coping with Asthma Study: a randomised controlled trial of a home based, nurse led psychoeducational intervention for adults at risk of adverse asthma outcomes
}

\author{
J R Smith, S Mildenhall, M J Noble, L Shepstone, M Koutantii, M Mugford, \\ B D W Harrison
}

Thorax 2005;60:1003-1011. doi: 10.1136/thx.2005.043877

See end of article for authors' affiliations

....................

Correspondence to: Ms J R Smith, School of Medicine, Health Policy and Practice, University of East Anglia, Norwich NR4 7TJ, UK; j.r.smith@ vea.ac.uk

Received 17 March 2005 Accepted 19 July 2005 Published Online First 29 July 2005

Background: Morbidity and mortality associated with severe asthma might be reduced by interventions that address psychosocial factors contributing to adverse outcomes. A study was undertaken to assess the effectiveness of a 6 month home based psychoeducational intervention delivered by a respiratory nurse specialist for adults at risk of adverse asthma outcomes.

Methods: A pragmatic randomised controlled trial was performed in 92 adults registered with hospital or primary care asthma clinics. All had previous hospital admissions and/or were on British Thoracic Society step 4-5 treatment and had failed to attend clinic appointments or were considered to have poor adherence to other aspects of their agreed management. Patients were visited in their homes for assessment and, where appropriate, intervention. The main outcomes measured were symptom control, asthma specific quality of life, and generic health status.

Results: At the 6 month primary time point there were no significant differences between usual care and intervention groups in mean symptom control, physical functioning, or mental health scores (differences (with $95 \% \mathrm{Cl}$ ) -0.35 (-1.83 to 1.13), 3.10 (-11.42 to 17.63$), 0.42(-10.22$ to 11.07$)$, respectively). Small effects on asthma specific quality of life up to 12 months (e.g. adjusted difference at 12 months 0.13 (95\% $\mathrm{Cl} 0.02$ to 0.25$)$ ) and short term effects on generic health status, which mirrored improvements in aspects of self-care observed at the end of the intensive phase of the intervention, were apparent only from fully adjusted analyses.

Conclusions: A home based intervention provided by a nurse receiving psychological supervision may have effects on quality of life but is overall of limited long term benefit to adults at risk of adverse asthma outcomes.

D espite effective drug treatments and management guidelines, ${ }^{1}$ a significant minority of asthma patients suffer from severe or poorly controlled disease. In 10\% of patients, symptoms remain inadequately controlled even with good clinical management. ${ }^{2}$ Of the $20 \%$ on the three highest treatment steps, ${ }^{3} 40 \%$ experience daily symptoms and significantly reduced quality of life. ${ }^{2}$ The burden of severe or poorly controlled asthma is most evident, however, through its adverse consequences. Asthma deaths represent a major cause of preventable mortality with around 1500 per year in the UK. ${ }^{2}$ Hospital admissions for asthma have stabilised since the early 1990s, but there were still nearly 74000 in $1999 .{ }^{2}$ Small numbers of those admitted require intensive care, indicative of near-fatal asthma. ${ }^{4}$

Most patients who suffer fatal and near-fatal attacks or are admitted to hospital have severe disease, indicated by use of three or more classes of asthma drugs ${ }^{5}$ and/or previous admissions. ${ }^{5-7}$ The role of psychosocial factors in contributing to these adverse outcomes has also become increasingly apparent. Case series studies consistently identify significant psychological or social problems in over $70 \%$ of patients suffering fatal or near-fatal attacks. ${ }^{4-10}$ In case-control studies, deficiencies in self-management and non-attendance at appointments are key risk factors for near-fatal ${ }^{11}$ and fatal asthma, ${ }^{12}$ respectively. In a study of admitted patients, management errors leading to hospitalisation mainly reflected poor self-care which was predicted by social, economic and psychological characteristics. ${ }^{13}$ Poor adherence to medical or self-care recommendations thus appears to be a key mechanism through which psychosocial factors influence asthma outcomes. ${ }^{74}$ Increasing research also highlights plausible neuroimmunological pathways by which psychological states directly affect pathophysiological mechanisms implicated in allergic and non-allergic asthma. ${ }^{15}$

With increasing emphasis on patient self-management of asthma, ${ }^{1}$ programmes designed to promote adherence and enhance self-care skills have proliferated. ${ }^{16}$ A Cochrane review of 36 trials concluded that self-management education is effective in improving health outcomes in general adult asthma populations. ${ }^{16}$ However, there is limited high quality evidence on other types of interventions addressing psychosocial issues resulting from, or impacting on, asthma. ${ }^{17}$ Furthermore, findings from most existing studies are unlikely to be generalisable to patients at risk of adverse outcomes in whom a complex interplay of clinical and psychosocial factors frequently complicate management and who are thus often excluded from, or fail to attend, standard programmes. $^{18}$

It is unclear whether psychoeducational interventions are likely to be more effective, given the greater capacity to benefit, $^{19}$ or less effective, given potential psychosocial barriers to education and behaviour change, ${ }^{12} 132021$ in atrisk groups. Our recent systematic review of psychoeducational interventions for severe and difficult asthma provided 
some evidence of effects on hospital admissions..$^{22}$ However, particularly in adults, there was limited evidence of impacts on other outcomes and the majority of research and greatest effects were confined to patients with severe disease who lacked other characteristics likely to put them at risk.

In response to the need for interventions targeting adults at risk of adverse asthma outcomes, we have run clinics staffed by a chest physician and psychiatrist since 1987. ${ }^{23}$ However, patients sometimes choose not to attend these and this study represents an evaluation of a previously piloted outreach approach ${ }^{24}$ that evolved from the joint consultations. We aimed to determine, through a randomised controlled trial, the effectiveness (in terms of symptom control and quality of life) of a psychoeducational programme delivered by a specialist respiratory nurse compared with routine care.

\section{METHODS}

\section{Participants}

Patients were identified between December 1999 and December 2001 from adult asthma clinics at five hospitals in Norfolk and Suffolk and 10 general practices in Norfolk, UK (fig 1). All had a confirmed diagnosis and severe asthma indicated by one or more previous hospital admissions for asthma and/or current prescription of British Thoracic Society (BTS) step 4 or 5 treatment. ${ }^{3}$ These indicators have been used elsewhere. ${ }^{15-7}$ In addition, patients had failed to attend routine appointments on two or more occasions in close succession and/or were judged by the clinician most closely involved in their care to be poorly adherent with their recommended management in other ways previously highlighted as important in identifying patients potentially at risk of adverse events. ${ }^{167}$ The latter judgement was made on the basis of evidence (such as a record in the notes or blood tests) of patients not taking medication and/or, where considered central to effective management, not monitoring their asthma as agreed.

A parallel study to validate our selection criteria confirmed that the combined indicators of severity and clinician identified poor adherence identified a group with clinical and psychosocial characteristics likely to put them at risk of adverse events. ${ }^{25}$

Ethical approval for this study was obtained from local research ethics committees in Norfolk and Suffolk, now represented by the Norwich local research ethics committee, Great Yarmouth \& Waveney local research ethics committee, and Suffolk local research ethics committee. Identified patients were sent a letter of invitation to participate with a detailed information sheet about the aims, content, and requirements of the study written according to UK research guidelines (http://www.corec.org.uk/applicants/help/docs/ Guidance_on_Patient_Information_Sheets_and_Consent_ Forms.doc). Non-respondents were sent a further letter and, as appropriate, followed up directly during any hospital

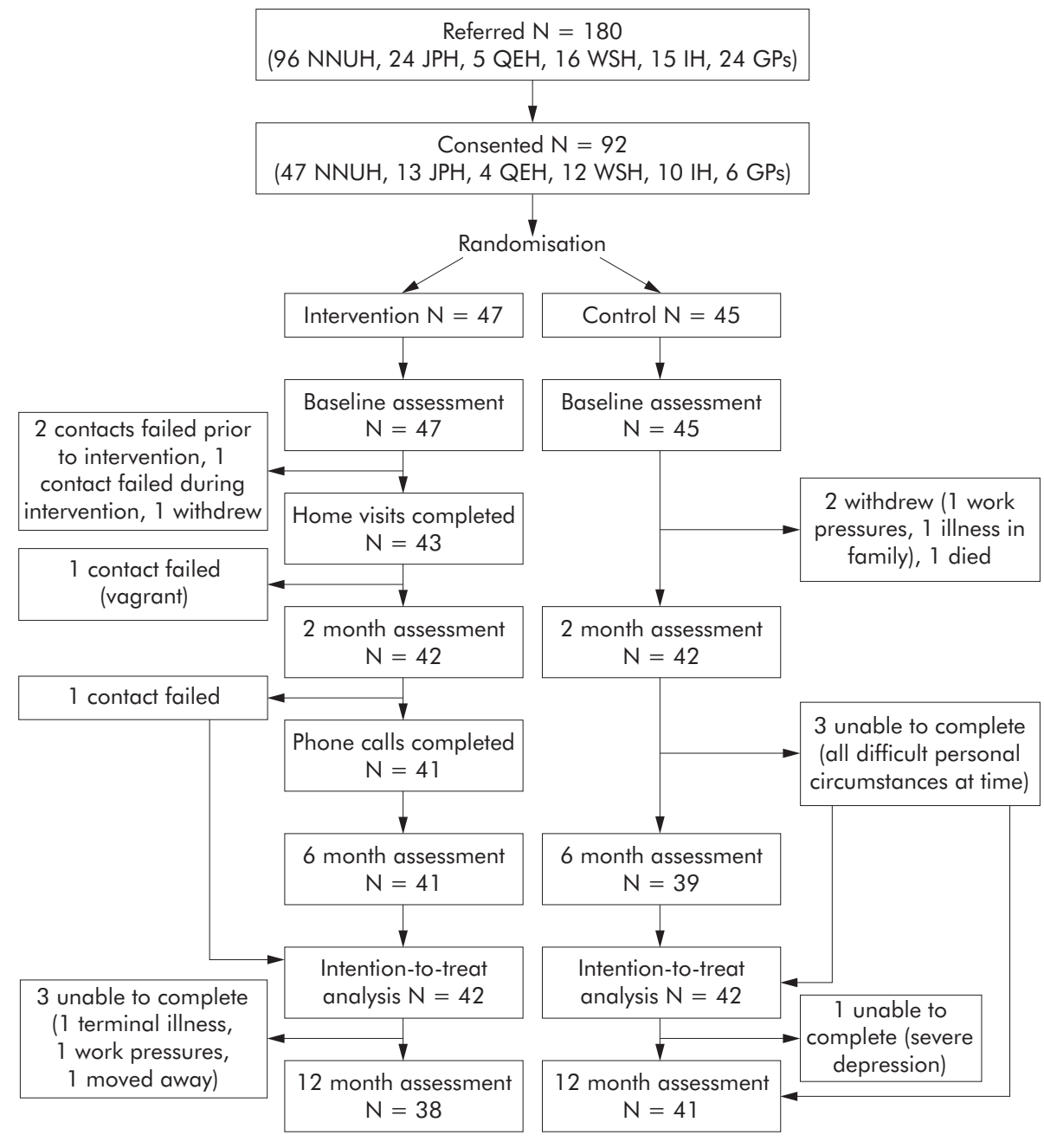

Figure 1 Patient recruitment, participation and follow up. NNUH, Norfolk \& Norwich University Hospital; JPH, James Paget Hospital; QEH, Queen Elizabeth Hospital; WSH, West Suffolk Hospital; IH, Ipswich Hospital; GPs, general practitioners. 
or clinic attendances or via their general practitioner if they failed to attend. Patients gave written consent to participate.

\section{Design}

The study was a pragmatic randomised controlled trial (that is, to assess effectiveness as it would be as part of normal care) of a home based programme delivered by a respiratory nurse specialist (intervention) compared with usual care (control). It was open (unblinded) since additional liaison with health professionals involved in the care of study patients often formed part of the intervention. Consenting patients were randomised by a university based researcher not involved in patient care (JS) using open computer generated block randomisation lists stratified by recruitment source (five hospitals, general practice).

\section{Intervention}

Control patients continued with routine asthma care provided by primary and secondary health services according to local arrangements. This generally comprised scheduled reviews at hospital and/or general practice based asthma clinics every 3-6 months and use of emergency and inpatient services as needed. At one hospital (James Paget), respiratory nurse specialists undertook occasional home visits to small numbers of patients.

In addition to usual care, intervention patients received a 6 month psychoeducational programme of home visits and telephone calls from a supervised respiratory nurse specialist (SM). Further details are provided in box 1 .

\section{Outcomes and process variables}

Data on all outcomes and process variables were collected from patients after randomisation (baseline) and at approximately 2 months (after completion of intervention home visits), 6 months (after completion of intervention follow up calls), and 12 months from baseline. Assessment visits were conducted by the study researcher (JS) in patients' homes between December 1999 and January 2003. Patients completed a face-to-face structured interview to assess use of health care services and performance of self-care (e.g. asthma monitoring, trigger avoidance) and other health related behaviours (e.g. smoking, exercise, weight control) and a series of self-administered questionnaires. For practical reasons related to study coordination, the fact that most outcomes were self-reported and that close contact of the researcher with patients was likely to result in awareness of group allocation, no attempts were made to blind the assessment.

The primary outcome was asthma symptom control assessed via recommended asthma morbidity questions. ${ }^{26}$ These involved patients rating the frequency of their night time symptoms, daytime symptoms, and interference of symptoms with usual activities in the last month on scales of 0 (no occurrence of symptoms/interference) to 3 (symptoms/ interference most days) that were totalled to produce an overall score. Secondary outcomes were asthma specific quality of life assessed using the Living with Asthma Questionnaire $^{27}$ and generic health status assessed using the Short-Form 36 (SF-36). ${ }^{28}$

Questionnaires were also administered to document standard baseline sociodemographic/socioeconomic details and to assess process variables. Psychological morbidity was measured using the Hospital Anxiety and Depression Scale $(\mathrm{HADS})^{29}$ and the General Health Questionnaire-12 (GHQ$12),{ }^{30}$ which produce anxiety and depression and psychiatric morbidity scores, respectively, and have cut off values for clinical caseness. Validated questionnaires to assess patient's perceptions of control over asthma ${ }^{31}$ and medication adherence $^{32}$ provided further insight into self-management activities. Further data were also collected for an economic evaluation yet to be reported.

\section{Statistical analyses}

Data were entered into SPSS for Windows and screened. Small numbers of individual missing questionnaire items were replaced with sample medians to allow calculation of total scores for each scale. The 6 month follow up served as the primary time point for analyses of primary and secondary outcomes. Between group differences were analysed using analyses of variance models. These incorporated referral source as a random factor to take account of the stratified nature of the data, and were conducted with and without adjustment for major differences between groups at baseline. Analyses were undertaken including all patients with complete follow up and additionally using a modified intention-to-treat approach by including data from the last assessed time point for all patients who had at least some follow up. Descriptive statistics only (means with standard deviations (SD) or medians with interquartile ranges (IQR)) are presented for process variables to avoid multiple hypothesis testing.

A sample size of 45 patients per group provided $80 \%$ power to detect a mean difference of 1.5 in the symptom control scores (based on a mean standard deviation of 2.54 ) $^{25}$ and 0.22 in the asthma specific quality of life scores (based on a mean standard deviation of 0.37). ${ }^{25}$ Although minimal clinically important differences for these scales have not yet been determined, a reduction of 1 in the symptom control score equates to a shift in patients experiencing symptoms in one of the three domains assessed (night time, daytime, or interference with activities) from "most days" to "once or twice a week", from "once or twice a week" to "once or twice a month", or from "once or twice a month" to "never". A difference of 0.22 in the asthma specific quality of life score equates to a moderate effect size, comparable to that seen as a result of pharmacological treatment. ${ }^{33}$ The differences the study was powered to detect were half the magnitude of those observed in comparing the trial patients with a group with well managed and controlled severe asthma, ${ }^{25}$ but were still deemed likely to be clinically meaningful.

\section{RESULTS}

\section{Patient flow}

One hundred and eighty patients were referred to the study; $92(51 \%)$ consented to participate and were randomised to control $(\mathrm{N}=45)$ and intervention $(\mathrm{N}=47)$ groups (fig 1). All participants provided baseline data. Eight (9\%) failed to provide any follow up data and were not included in intention-to-treat analyses. There were no clear differences between these and patients completing the study.

\section{Sample characteristics in light of selection criteria}

Over half the participants $(\mathrm{N}=48)$ met the study criteria for severe asthma on the basis of both having had previous hospital admissions for asthma and being prescribed BTS step 4-5 treatment. Thirty (33\%) met the criteria on the basis of previous admissions alone and $14(15 \%)$ on the basis of their treatment alone. Two thirds of participants $(\mathrm{N}=61)$ met additional selection criteria as a result of having repeatedly failed to attend routine appointments. One quarter $(\mathrm{N}=23)$ were identified as poorly compliant on the basis of evidence suggesting they failed to adhere to medications alone. Only seven $(8 \%)$, in whom objective monitoring was deemed central to effective management, were identified as poorly compliant as a result of failing to monitor asthma alone. Nearly $40 \%(\mathrm{~N}=34)$ met two or more of the nonattendance/poor adherence criteria. 
Box 1 Details of home based, nurse led psychoeducational intervention

Aims and rationale

The intervention ultimately aimed to improve patients' control of asthma symptoms and quality of life by (1) establishing/ increasing adherence to an agreed self-management plan (including optimal use of medications, health services and peak flow/symptom monitoring) and (2) establishing/ reinforcing adaptive strategies for coping with asthma and related problems and supporting positive health related behaviours. It was envisaged that this would be achieved by providing education, skills training and support, exploring cognitions, and intervening at a practical level with individual psychological, social, economic or medical problems which might compromise the above. The nature and delivery of the programme was informed by existing literature on asthma intervention approaches which have drawn on a range of psychological theories underpinning health related behaviour change and coping. ${ }^{161722}$

\section{Personnel}

Provider: The intervention was delivered by a single respiratory nurse specialist (SM) with $20+$ years experience of respiratory medicine in primary and secondary care settings. The nurse had completed the UK National Respiratory Training Centre (NRTC) diploma in asthma care in 1995 and further relevant professional development courses in nursing practice, respiratory medicine, research and psychological aspects of disease management (including the NRTC course on Psychology of Asthma Compliance).

Supervision: Clinical and psychological supervision was provided to assist in identifying and advising on strategies to address problems compromising effective asthma management. The supervisors were (1) a general practitioner who undertakes regular liaison psychiatry sessions ${ }^{23}$ in the respiratory department of a local acute hospital trust (MN), and (2) a health psychologist (MK) trained in counselling and with research and treatment experience in managing chronic diseases using a cognitive behavioural approach. One or both of the supervisors met with the nurse approximately monthly and provided additional telephone support as needed.

\section{Format}

Setting: Patients were seen in their homes or at other sites as nominated, given individual circumstances at the time (for example, small numbers were visited on one or more occasion at their workplace, at a friend's or family member's home, at a drop-in centre, or in hospital).

Schedule and duration: Four 2-weekly visits for 2 months were supplemented, where possible, by brief 2-weekly telephone calls between visits and monthly telephone calls for 4 months thereafter. After an initial visit of approximately 90 minutes (range 60-120), visits lasted about 1 hour (range 20-150 minutes). Patients were also able to contact the nurse directly as needed. The duration of the intervention was 6 months in total and approximated to an average of 5.5 hours of direct contact for those completing it.

\section{Content}

General: The intervention provided asthma education (e.g. physiology, medications, triggers), training in self-management skills (e.g. inhaler technique, use of peak flow meter, attack management, trigger control, better breathing), advice on coping with asthma and associated difficulties, and support in identifying, prioritising and addressing other factors compromising effective management. It included involvement of family members, liaison with health and social care professionals, or referral to specialist medical, psychiatric or social services where indicated.

Visit 1 "Understanding asthma": Exploration of patients' medical history, self-care and other health related behaviours, cognitions (e.g. knowledge, beliefs, attitudes), emotional status, social circumstances, and life goals to aid in identifying and prioritising factors that might be addressed to improve management of asthma and to reinforce the need for good asthma control. Patients usually agreed to monitor peak flow or symptoms to support development of an individualised self-management plan if they did not already have one, and began to set initial short term goals.

Visit 2 "Taking steps to improve asthma": Recap on and reinforcement of previous issues discussed, development of an individualised symptom or peak flow based self-management plan, discussion of relationships and communication with health professionals, identification and prioritisation of agreed goals, and provision of information, education, skills training and additional support (e.g. involvement of others, referral to other services) to address barriers to implementing goals.

Visit 3 "Gaining control of asthma": Recap on and reinforcement of previous issues, review of progress with goals, identification of any problems with these, and provision of further information, education, skills training, and support as necessary to encourage patients to continue with agreed goals.

Visit 4 "Looking to a future with well-controlled asthma": Recap on and reinforcement of previous issues, discussion of long term use of a self-management plan, exploration of possible future barriers to implementation of goals, reinforcing confidence in maintaining any changes made, agreeing next steps, and ensuring next appointment scheduled with local asthma clinic.

Telephone calls: These served a reinforcing and supportive role throughout.

\section{Delivery}

Delivery methods: A collaborative problem solving approach was used whereby the patient and nurse set agreed goals and jointly developed strategies to achieve them (with advice from the supervisors). Verbal interactions were supplemented with a patient workbook, including optional "homework" linked to the content of the visits, and additional published written information and instruction on asthma and individually relevant topics such as medications, triggers, smoking, better breathing, relaxation techniques, and exercise.

Standardisation: A manual (available on request) was used to standardise delivery and general content of the intervention and to document issues arising from individual discussions, agreed goals, and difficulties and points for action or discussion at supervisory meetings. Within a general framework including core content on asthma, medications and selfmanagement, the manual allowed the intervention to be individualised to specific needs. A subsample of visits were tape recorded to investigate fidelity of the intervention.

\section{Representativeness of sample}

Compared with consenting patients, a higher proportion of non-participants $(86 \%)$ met study selection criteria on the basis of failing to attend appointments but they were similar with respect to other criteria. There was a higher proportion of women in the recruited sample $(73 \%)$ than in nonparticipating patients $(41 \%, \mathrm{p}<0.001)$. Data available from 72 of the 88 non-participants suggested no differences in mean (SD) age (36.5 (10.7) $v 34.3$ (10.6) years respectively, $\mathrm{p}=0.20)$. 
Table 1 Baseline characteristics of control and intervention group patients

\begin{tabular}{|c|c|c|c|}
\hline & $\begin{array}{l}\text { Control group } \\
(\mathrm{N}=45)\end{array}$ & $\begin{array}{l}\text { Intervention group } \\
(\mathrm{N}=47)\end{array}$ & $\begin{array}{l}\text { Total } \\
(\mathrm{N}=92)\end{array}$ \\
\hline \multicolumn{4}{|l|}{ Sociodemographic/economic characteristics } \\
\hline Female sex & $38(84)$ & $29(62)$ & $67(73)$ \\
\hline Mean (SD) age (years) & $34.7(10.2)$ & $38.2(11.1)$ & $36.5(10.7)$ \\
\hline White ethnic background & $45(100)$ & $45(96)$ & $90(98)$ \\
\hline $\begin{array}{l}\text { Living in adverse family circumstances } \\
\text { (currently divorced/separated/single parent) }\end{array}$ & $13(29)$ & $15(32)$ & $28(30)$ \\
\hline Left full time education aged $\leqslant 16$ years & $28(64)$ & $40(85)$ & $68(75)$ \\
\hline Currently employed outside the home & $17(38)$ & $20(43)$ & $37(40)$ \\
\hline Net family income $<£ 300$ per week & $28(64)$ & $34(72)$ & $62(68)$ \\
\hline $\begin{array}{l}\text { Household in receipt of welfare benefits } \\
\text { (including child benefit) }\end{array}$ & $40(89)$ & $39(83)$ & $79(86)$ \\
\hline Living in public housing & $16(36)$ & $19(40)$ & $35(38)$ \\
\hline \multicolumn{4}{|l|}{ Clinical characteristics } \\
\hline Mean (SD) years with asthma & $20.5(12.0)$ & $23.0(10.6)$ & $21.8(11.3)$ \\
\hline $\begin{array}{l}\text { Admission or accident and emergency } \\
\text { attendance for asthma in prior } 6 \text { months }\end{array}$ & $17(38)$ & $29(62)$ & $46(50)$ \\
\hline Median (IQR) daily dose of inhaled $\beta$ agonist ( $\mu \mathrm{g})$ & $1250(4975)$ & $1100(5600)$ & $1250(5150)$ \\
\hline $\begin{array}{l}\text { Median (IQR) daily dose of inhaled steroids ( } \mu \mathrm{g} \\
\text { beclometasone equivalent) }\end{array}$ & $2000(2000)$ & $2000(3000)$ & 2000 (2475) \\
\hline Currently taking oral steroids & $24(53)$ & $26(55)$ & $50(54)$ \\
\hline Taking other (non-asthma) medications & $38(84)$ & $34(72)$ & $72(78)$ \\
\hline $\begin{array}{l}\text { Reaching HADS score for moderate to severe } \\
\text { anxiety }(11+)\end{array}$ & $16(36)$ & $17(36)$ & $33(36)$ \\
\hline $\begin{array}{l}\text { Reaching HADS score for moderate to severe } \\
\text { depression }(11+)\end{array}$ & $5(11)$ & $8(17)$ & $13(14)$ \\
\hline $\begin{array}{l}\text { Reaching GHQ-12 score for possible psychiatric } \\
\text { caseness }(6+)\end{array}$ & $13(29)$ & $17(36)$ & $30(33)$ \\
\hline
\end{tabular}

\section{Baseline characteristics}

The baseline characteristics of the patients in the control and intervention groups are shown in table l. There were higher proportions of men, patients who had left full time education at age 16 years or less, and patients who had been admitted to hospital or attended the accident and emergency department for asthma in the last 6 months in the intervention group than in the control group. These differences were adjusted for in analyses as planned. No other major differences in baseline sociodemographic, socioeconomic, or clinical characteristics were apparent.

\section{Primary and secondary health outcomes}

At 6 months (mean (SD) follow up 201 (17) days), planned analyses provided no evidence of differences between the groups with respect to asthma symptoms, asthma specific quality of life, or SF-36 physical functioning and mental health subscale scores (table 2). Adjustment for major baseline differences between groups and removal of data from four patients missing the 6 month follow up did not alter the results. Furthermore, similar analyses suggested there were no statistically significant differences in health outcomes between the groups at 2 months (mean (SD) follow up 76 (13) days) or 12 months (mean (SD) follow up 382 (15) days); adjusted analyses are shown in table 3.

Planned analyses were supplemented with analyses which additionally adjusted for baseline outcome scores. These did not alter the findings with respect to asthma symptoms but provided evidence of effects on asthma specific quality of life and SF-36 subscales at 2 months. Only effects on asthma specific quality of life remained consistently significant up to 12 months (table 4).

\section{Process variables}

Descriptive statistics (table 5) suggest that the intervention led to a reduction in the proportion of patients using their reliever inhaler more than four times per day and an increase in the proportion monitoring their peak flow at 2 months.

Table 2 Mean (SD) scores and results of planned intention-to-treat analyses comparing health outcomes in control and intervention groups at 6 month primary study end point

\begin{tabular}{|c|c|c|c|c|c|c|c|c|}
\hline & \multicolumn{2}{|l|}{ Baseline } & \multicolumn{6}{|l|}{6 months } \\
\hline & $\begin{array}{l}\text { Control } \\
(\mathrm{N}=47)\end{array}$ & $\begin{array}{l}\text { Intervention } \\
(\mathrm{N}=45)\end{array}$ & $\begin{array}{l}\text { Control } \\
(\mathrm{N}=42)\end{array}$ & $\begin{array}{l}\text { Intervention } \\
(\mathrm{N}=42)\end{array}$ & $\begin{array}{l}\text { Unadjusted } \\
\text { difference* } \\
(95 \% \mathrm{Cl})\end{array}$ & p value* & $\begin{array}{l}\text { Adjusted difference } † \\
(95 \% \mathrm{Cl})\end{array}$ & p valuet \\
\hline \multicolumn{9}{|l|}{ Primary outcome } \\
\hline $\begin{array}{l}\text { Asthma symptom control score } \\
\text { (range 0-9, lower = better) }\end{array}$ & $\begin{array}{l}5.11 \\
(3.00)\end{array}$ & $\begin{array}{l}6.06 \\
(3.11)\end{array}$ & $\begin{array}{l}4.00 \\
(2.91)\end{array}$ & $\begin{array}{l}4.21 \\
(3.50)\end{array}$ & $\begin{array}{l}-0.20 \\
(-1.54 \text { to } 1.14)\end{array}$ & 0.77 & $\begin{array}{l}-0.35 \\
(-1.83 \text { to } 1.13)\end{array}$ & 0.64 \\
\hline \multicolumn{9}{|l|}{ Secondary outcomes } \\
\hline $\begin{array}{l}\text { Asthma quality of life score } \\
\text { (range } 0-2 \text {, lower }=\text { better) }\end{array}$ & $\begin{array}{l}1.14 \\
(0.40)\end{array}$ & $\begin{array}{l}1.20 \\
(0.41)\end{array}$ & $\begin{array}{l}1.04 \\
(0.40)\end{array}$ & $\begin{array}{l}1.02 \\
(0.45)\end{array}$ & $\begin{array}{l}0.03 \\
(-0.15 \text { to } 0.21)\end{array}$ & 0.74 & $\begin{array}{l}0.05 \\
(-0.16 \text { to } 0.25)\end{array}$ & 0.65 \\
\hline $\begin{array}{l}\text { SF-36 physical function score } \\
\text { (range } 0-100, \text { higher = better) }\end{array}$ & $\begin{array}{l}55.33 \\
(26.83)\end{array}$ & $\begin{array}{l}50.85 \\
(31.46)\end{array}$ & $\begin{array}{l}55.36 \\
(29.56)\end{array}$ & $\begin{array}{l}52.98 \\
(31.59)\end{array}$ & $\begin{array}{l}1.97 \\
(-11.38 \text { to } 15.33)\end{array}$ & 0.77 & $\begin{array}{l}3.10 \\
(-11.42 \text { to } 17.63)\end{array}$ & 0.67 \\
\hline $\begin{array}{l}\text { SF-36 mental health score } \\
\text { (range } 0-100 \text {, higher = better) }\end{array}$ & $\begin{array}{l}62.49 \\
(22.14)\end{array}$ & $\begin{array}{l}58.81 \\
(23.01)\end{array}$ & $\begin{array}{l}66.19 \\
(20.82)\end{array}$ & $\begin{array}{l}66.19 \\
(22.30)\end{array}$ & $\begin{array}{l}-0.40 \\
(-9.98 \text { to } 9.18)\end{array}$ & 0.93 & $\begin{array}{l}0.42 \\
(-10.22 \text { to } 11.07)\end{array}$ & 0.94 \\
\hline
\end{tabular}


Table 3 Mean (SD) scores and results of planned intention-to-treat analyses comparing health outcomes in control and intervention groups at 2 and 12 months

\begin{tabular}{|c|c|c|c|c|c|c|c|c|}
\hline & \multicolumn{4}{|l|}{2 months } & \multicolumn{4}{|c|}{12 months } \\
\hline & $\begin{array}{l}\text { Control } \\
(\mathrm{N}=42)\end{array}$ & $\begin{array}{l}\text { Intervention } \\
(\mathrm{N}=42)\end{array}$ & $\begin{array}{l}\text { Adjusted difference* } \\
(95 \% \mathrm{CI})\end{array}$ & p value ${ }^{*}$ & $\begin{array}{l}\text { Control } \\
(\mathrm{N}=42)\end{array}$ & $\begin{array}{l}\text { Intervention } \\
(\mathrm{N}=42)\end{array}$ & $\begin{array}{l}\text { Adjusted difference* } \\
(95 \% \mathrm{CI})\end{array}$ & p value* \\
\hline \multicolumn{9}{|l|}{ Primary outcome } \\
\hline $\begin{array}{l}\text { Asthma symptom control } \\
\text { score (range 0-9, } \\
\text { lower = better) }\end{array}$ & $\begin{array}{l}5.00 \\
(3.08)\end{array}$ & $\begin{array}{l}4.29 \\
(3.26)\end{array}$ & $\begin{array}{l}0.52 \\
(-0.93 \text { to } 1.97)\end{array}$ & 0.48 & $\begin{array}{l}4.48 \\
(3.00)\end{array}$ & $\begin{array}{l}4.36 \\
(3.50)\end{array}$ & $\begin{array}{l}0.30 \\
(-1.18 \text { to } 1.78)\end{array}$ & 0.69 \\
\hline \multicolumn{9}{|l|}{ Secondary outcomes } \\
\hline $\begin{array}{l}\text { Asthma quality of life score } \\
\text { (range } 0-2 \text {, lower = better) }\end{array}$ & $\begin{array}{l}1.08 \\
(0.41)\end{array}$ & $\begin{array}{l}1.04 \\
(0.43)\end{array}$ & $\begin{array}{l}0.06 \\
(-0.14 \text { to } 0.26)\end{array}$ & 0.56 & $\begin{array}{l}1.02 \\
(0.44)\end{array}$ & $\begin{array}{l}1.01 \\
(0.45)\end{array}$ & $\begin{array}{l}0.05 \\
(-0.16 \text { to } 0.26)\end{array}$ & 0.66 \\
\hline $\begin{array}{l}\text { SF-36 physical function } \\
\text { score (range 0-100, } \\
\text { higher = better) }\end{array}$ & $\begin{array}{l}51.67 \\
(28.08)\end{array}$ & $\begin{array}{l}55.71 \\
(33.21)\end{array}$ & $\begin{array}{l}-2.07 \\
(-16.53 \text { to } 12.38)\end{array}$ & 0.78 & $\begin{array}{l}58.45 \\
(30.01)\end{array}$ & $\begin{array}{l}55.83 \\
(33.98)\end{array}$ & $\begin{array}{l}1.79 \\
(-13.24 \text { to } 17.11)\end{array}$ & 0.80 \\
\hline $\begin{array}{l}\text { SF-36 mental health } \\
\text { score (range 0-100, } \\
\text { higher = better) }\end{array}$ & $\begin{array}{l}62.57 \\
(21.16)\end{array}$ & $\begin{array}{l}64.86 \\
(22.60)\end{array}$ & $\begin{array}{l}-2.77 \\
(-13.35 \text { to } 7.81)\end{array}$ & 0.60 & $\begin{array}{l}63.81 \\
(23.90)\end{array}$ & $\begin{array}{l}66.38 \\
(24.36)\end{array}$ & $\begin{array}{l}-3.38 \\
(-14.88 \text { to } 8.13)\end{array}$ & 0.56 \\
\hline
\end{tabular}

Differences between groups in the proportions monitoring their peak flow were reduced but still apparent at 6 and 12 months. There were no clear differences with respect to other variables at any time points.

\section{DISCUSSION \\ Principal findings}

This study took a pragmatic approach to the identification of patients potentially at risk from their asthma using severity and poor adherence criteria that can be readily applied in routine practice. Baseline data indicate success in recruiting patients sharing characteristics such as poor asthma control, physical and psychological co-morbidities, inadequate selfmanagement, and social difficulties with those experiencing adverse outcomes in previous studies. ${ }^{4-13}$ Furthermore, an accompanying comparative study using baseline data from the trial patients ${ }^{25}$ suggests that these characteristics are not shared by patients with severe asthma judged to be managing their asthma well. Non-attendance at scheduled appointments and other forms of clinician identified poor adherence thus appear to be useful in identifying patients with severe asthma who are likely to be at particularly high risk of experiencing adverse events. ${ }^{12} 1325$

A relatively intensive psychologically based but pragmatic intervention, tailored to the needs of this at-risk group and the individuals within it, was of no clear benefit in improving control of asthma symptoms up to 12 months compared with usual care. Consistent impacts of the intervention on asthma specific quality of life up to 12 months and short term effects on dimensions of generic health status were apparent only when analyses adjusted for baseline outcomes scores. Although they must therefore be interpreted with caution, the short term impacts on secondary health outcomes mirror improvements in some aspects of self-care behaviour observed at the end of the intensive phase of the intervention.

We conducted a thorough evaluation and assessment of effectiveness with outcome measures that $\mathrm{we}^{25}$ and others ${ }^{26-33}$ have previously shown to be sensitive to important effects that the intervention may have delivered. Differences in generic health status dimensions at 2 months and possibly in mental health scores at 12 months are of a magnitude previously identified as clinically important. ${ }^{34}$ However, it is unclear whether the small differences in asthma specific quality of life, although statistically significant, are clinically meaningful. It should be noted that none of the differences observed approached the magnitude of those seen in comparing the trial patients with a group with severe asthma that was well managed and controlled. ${ }^{25}$ Overall, there is no clear evidence that the intervention had clinically important impacts on health outcomes in the longer term.

\section{Strengths and weaknesses of the study}

To increase the generalisability of our results we explicitly targeted patients frequently excluded, by design or default, from other studies of psychoeducational interventions, even in severe asthma (for example, patients with co-morbidities, psychiatric problems, smokers). ${ }^{22}$ Despite being difficult to engage, we had some success in recruiting, delivering an intervention to, and following up the majority of these patients. However, our sample may not be entirely representative of the target population since non-participants were less likely to be female or to attend routine appointments. Since they did not consent to any assessment, we do not have further data on eligible patients who did not participate, but they may represent a harder to reach at risk subgroup to whom these results might not be generalisable.

Although delivered by a single nurse who received specific supervision, our intervention was designed to be replicable for provision by suitably qualified nurses with specialist asthma training under the guidance of clinicians with generic psychological or psychiatric expertise. The multicentre design of our study also means that, because of the variable nature of the usual care with which the intervention was compared, our findings are likely to be generalisable to a range of primary and secondary healthcare settings.

Despite randomisation, asthma morbidity, general health and psychosocial circumstances were generally slightly worse in the intervention than in the control group at baseline. Such imbalances are common in small trials and, for this reason, we had planned to adjust in our analyses for any major differences likely to be correlated with outcome scores (such as recent admission/emergency attendance). However, unplanned analyses suggested that findings for our secondary health outcomes were sensitive to additional adjustment for the minor disparities in these outcomes between groups at baseline. We therefore cannot discount the possibility that small baseline differences in psychological morbidity and perceived control of asthma may also have masked some small effects of the intervention on these process variables, although this was not formally assessed.

The eventual number of patients available for analyses fell slightly short of our estimated sample size requirements and was inevitably relatively small, given the difficulty inherent in recruiting the type of patients targeted (that is, poorly compliant). This meant that confidence intervals around our outcome estimates were wide and do not exclude the 


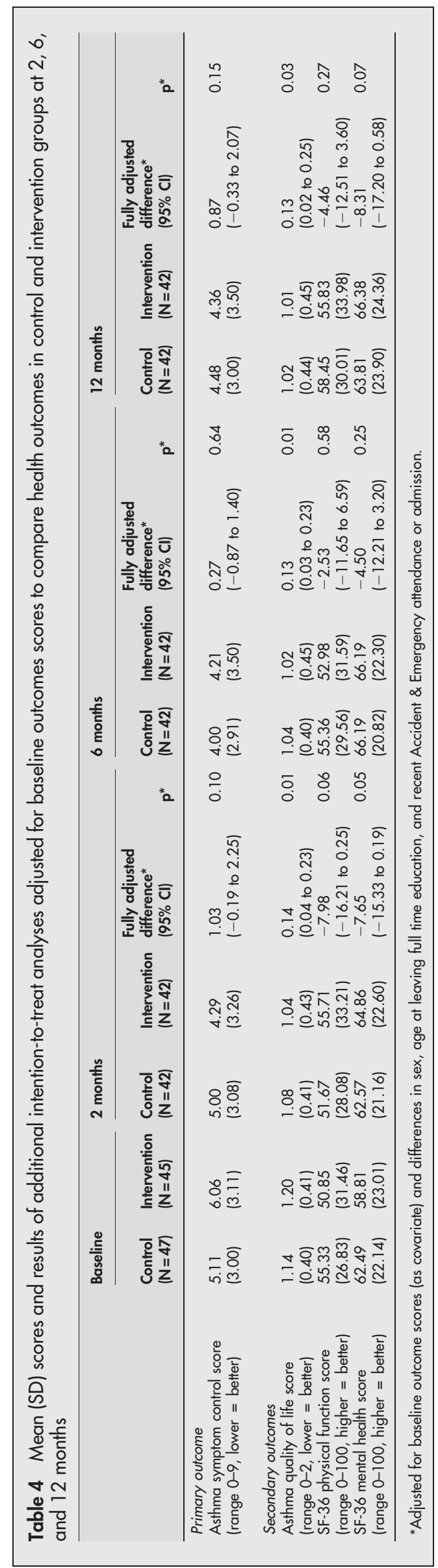

possibility that the intervention had more important impacts on health outcomes and that type II errors have thus been made. The lack of apparent effects on asthma symptom control might also stem from the assessment tool used. ${ }^{26}$ Although able to discriminate between our trial patients and a group with severe asthma that was well managed and controlled, ${ }^{25}$ its responsiveness is yet to be fully evaluated.

There is a possibility that a "placebo effect" resulting from the assessment visits to control patients may have further masked differences between the groups since there are some small improvements in primary health outcomes in both groups over time. However, in the absence of longitudinal data from comparable patients who did not receive assessment visits, we cannot discount the fact that these changes might be explained in terms of regression to the mean as a result of patients at an extreme in terms of morbidity being targeted. ${ }^{35}$ This phenomenon must also be borne in mind in considering reports of greater effects from similar interventions among at risk groups in studies that have not been so rigorously designed, and particularly in those lacking prospective control groups. ${ }^{22}$ Our findings are largely consistent with controlled studies targeting similar patients but, probably because of the difficulties in conducting them, there remains a paucity of high quality trials in this area. ${ }^{22}$

\section{Implications of the study}

This study has highlighted the difficulties faced by patients with severe or poorly controlled asthma who fail to attend appointments and in whom psychosocial problems compromise their ability to manage their asthma in other ways. It emphasises the need for awareness of these issues in the routine care of these patients and, given shortfalls identified in medical care as a result of implementing our intervention, that there is room for this to be improved. One approach might be to ensure better integration with, or delivery of, interventions in primary care or emergency settings where there is increased scope for "opportunistic" intervention with patients who fail to attend routine appointments. We are currently exploring use of a tool to capitalise on opportunistic contacts with at risk asthma patients in general practice.

Although attempts were made to address them, the variety, complexity and intractable nature of problems faced by many of the patients targeted might explain why our intervention, in contrast to some of those in general asthma samples, ${ }^{16}$ did not demonstrate consistent long term effects. However, the heterogeneity of the group and evidence for short term impacts on self-care, and possibly health outcomes, may point to the value of continuing intensive support in selected patients. Further analyses are underway to increase understanding of the characteristics of this group, investigate which patients are most likely to benefit from interventions of this type, and to explore additional quantitative and qualitative data on potential benefits of our programme. The large cost implications of providing any intervention, and whether this represents a good use of healthcare resources, are also being explored in parallel economic evaluation studies.

Additional research on causal pathways by which psychosocial factors, adherence and asthma outcomes are linked, especially in complex patient groups, may also be necessary to guide the design, content and delivery of future interventions. Once the research base is sufficiently mature, there will be scope for the development and thorough evaluation of more powerful ongoing interventions that make more use of psychoeducational theories and techniques to target better the needs of groups that are hard to reach. Examination of the effects of the timing of the delivery of future interventions on the occurrence of adverse events also warrants investigation. 
Table 5 Psychological morbidity and self-management in control and intervention groups at baseline and 2, 6, and 12 months

\begin{tabular}{|c|c|c|c|c|c|c|c|c|}
\hline & \multicolumn{2}{|l|}{ Baseline } & \multicolumn{2}{|c|}{2 months } & \multicolumn{2}{|c|}{6 months } & \multicolumn{2}{|c|}{12 months } \\
\hline & $\begin{array}{l}\text { Control } \\
(N=47)\end{array}$ & $\begin{array}{l}\text { Intervention } \\
(N=45)\end{array}$ & $\begin{array}{l}\text { Control } \\
(N=42)\end{array}$ & $\begin{array}{l}\text { Intervention } \\
(\mathrm{N}=42)\end{array}$ & $\begin{array}{l}\text { Control } \\
(\mathrm{N}=42)\end{array}$ & $\begin{array}{l}\text { Intervention } \\
(N=42)\end{array}$ & $\begin{array}{l}\text { Control } \\
(N=42)\end{array}$ & $\begin{array}{l}\text { Intervention } \\
(\mathrm{N}=42)\end{array}$ \\
\hline \multicolumn{9}{|l|}{ Psychological morbidity } \\
\hline $\begin{array}{l}\text { Mean (SD) HADS anxiety score } \\
\text { (range 0-21 lower = better) }\end{array}$ & 9.13 & 9.49 & $\begin{array}{l}8.74 \\
(4.29)\end{array}$ & 8.52 & 8.14 & 8.02 & 8.71 & 8.17 \\
\hline Mean (SD) HADS depression score & $\begin{array}{l}14.221 \\
5.11\end{array}$ & 6.02 & $\begin{array}{l}14.291 \\
5.05\end{array}$ & 5.43 & $\begin{array}{l}(4.30) \\
4.12\end{array}$ & $\begin{array}{l}(5.32) \\
5.14\end{array}$ & $\begin{array}{l}(4.74) \\
4.76\end{array}$ & $\begin{array}{l}10.1 / 1 \\
4.83\end{array}$ \\
\hline (range $0-21$, lower = better) & (3.66) & (3.69) & (3.87) & (3.88) & $(3.20)$ & $(4.24)$ & $(4.18)$ & $(4.38)$ \\
\hline Mean (SD) GHQ-12 psychiatric morbidity & 14.20 & 15.36 & 14.33 & 12.98 & 11.74 & 13.31 & 13.38 & 12.86 \\
\hline \multicolumn{9}{|l|}{ Self-management } \\
\hline Using reliever inhaler $>4$ times/day & $23(51)$ & $27(57)$ & $17(41)$ & $9(21)$ & $11(26)$ & $15(36)$ & $15(36)$ & $14(33)$ \\
\hline Monitoring peak flow & $7(16)$ & $10(21)$ & $6(14)$ & $29(69)$ & $6(14)$ & $12(29)$ & $4(10)$ & $12(29)$ \\
\hline Currently smoking & $17(38)$ & $19(40)$ & $13(31)$ & $14(33)$ & $13(31)$ & $17(41)$ & $13(31)$ & $15(36)$ \\
\hline Identifying additional triggers & N/A & N/A & $15(36)$ & $18(43)$ & $10(24)$ & $9(21)$ & $13(31)$ & $13(31)$ \\
\hline Mean (SD) perceived control of asthma & 37.29 & 36.66 & 38.02 & 39.12 & 38.54 & 38.81 & 38.36 & 40.38 \\
\hline score (range $11-44$, higher = better) & (6.36) & (6.89) & $(5.97)$ & $(7.12)$ & (5.89) & $(6.54)$ & $(5.93)$ & $(6.41)$ \\
\hline Mean (SD) medication compliance score & 11.80 & 12.34 & 11.36 & 13.05 & 11.33 & 12.93 & 11.40 & 12.86 \\
\hline (range $0-16$, higher = better) & $(2.80)$ & (3.17) & $(3.40)$ & (3.31) & (3.54) & $(2.96)$ & (3.68) & $(3.06)$ \\
\hline
\end{tabular}

\section{ACKNOWLEDGEMENTS}

The authors acknowledge the three anonymous reviewers who so thoroughly reviewed an initial version of this paper, and thank all study participants and consultant physicians (Drs Tim Cotter, David Ellis, Russell Hall, Nick Innes, Clare Laroche, Mark Pasteur, Anna Pawlovicz, Crichton Ramsay, Douglas Seaton, Orion Twentyman, Simon Watkin), respiratory nurses (Simon Hodder, Claire Kent, Heather Matthews, Linda Pearce, Cathy Tooley), general practitioners, practice nurses, and hospital and practice secretarial staff who assisted with recruitment and supported the study. They also acknowledge the contribution of Professor Shirley Pearce who was involved in the initial design of the study.

\section{Authors' affiliations}

J R Smith, L Shepstone, M Mugford, B D W Harrison, School of

Medicine, Health Policy and Practice, University of East Anglia, Norwich NR4 7TJ, UK

S Mildenhall, B D W Harrison, Department of Respiratory Medicine, Norfolk \& Norwich University Hospital NHS Trust, Norwich NR4 7UY, UK

M J Noble, Acle Medical Centre, Acle, Norfolk NR13 3RA, UK M Koutantii, Department of Surgical Oncology and Technology, Imperial College, St Mary's Hospital, London W2 1NY, UK

This study was supported by a grant from the British Lung Foundation (grant number P99/2) with sponsorship from the National Lottery Community Fund. The work was undertaken independently of the funders.

\section{Competing interests: none.}

JS advised on selection of outcome measures, assisted with the design of the intervention, coordinated the study, collected data, conducted analyses, drafted and revised the paper, and is guarantor for the work. SM was involved in the conception of the study, developed, piloted and delivered the intervention and commented on drafts. MN assisted with the design of the intervention, provided supervision for the intervention, assisted with interpretation of results and commented on drafts. LS advised on study design, assisted with statistical analyses and interpretation of results and commented on drafts. MK assisted with selection of outcome measures, provided supervision for the intervention and commented on drafts. MM advised on study design and commented on drafts. BH developed the original study proposal, served as principal investigator, and assisted with interpretation of results and drafting of the paper. All authors approved the final manuscript.

\section{REFERENCES}

1 British Thoracic Society, Scottish Intercollegiate Guidelines Network. British guideline on the management of asthma. Thorax 2003;58(Suppl I):i1-i94.

2 National Asthma Campaign. Out in the open: a true picture of asthma in the United Kingdom today. Asthma J 2001;6:(3 Special Supplement).
3 British Thoracic Society, National Asthma Campaign, Royal College of Physicians of London. Guidelines for management of asthma: 1995 review and position statement. Thorax 1997;52(Suppl 1):S1-21.

4 Innes NJ, Reid A, Halstead J, et al. Psychosocial risk factors in near-fatal asthma and in asthma deaths. J R Coll Physicians Lond 1998;32:430-4.

5 Crane J, Pearce N, Burgess C, et al. Markers of risk of asthma death or readmission in the 12 months following a hospital admission for asthma. Int J Epidemiol 1992;21:737-44.

6 Wareham NJ, Harrison BDW, Jenkins PF, et al. A district confidential enquiry into deaths due to asthma. Thorax 1993;48:1117-20.

7 Mohan G, Harrison BDW, Badminton RM, et al. A confidential enquiry into deaths caused by asthma in an English health region: implications for general practice. Br J Gen Pract 1996;46:529-32.

8 Campbell DA, McLennan G, Coates JR, et al. A comparison of asthma deaths and near-fatal asthma attacks in South Australia. Eur Respir J 1994;7:490-7.

9 Richards GN, Kolbe J, Fenwick J, et al. Demographic characteristics of patients with severe life threatening asthma: comparison with asthma deaths. Thorax 1993;48:1 105-9.

10 Campbell DA, Yellowlees PM, McLennan G, et al. Psychiatric and medical features of near fatal asthma. Thorax 1995;50:254-9.

11 Kolbe J, Fergusson W, Vamos M, et al. Case-control study of severe life threatening asthma (SLTA) in adults: demographics, health care, and management of the acute attack. Thorax 2000;55:1007-15.

12 Sturdy PM, Victor CR, Anderson HR, et al. Psychological, social and health behaviour risk factors for deaths certified as asthma: a national case-control study. Thorax 2002;57:1034-9.

13 Kolbe J, Vamos M, Fergusson W, et al. Determinants of management errors in acute severe asthma. Thorax 1998:53:14-20.

14 Harrison BDW. Psychosocial aspects of asthma in adults. Thorax 1998;53:519-25.

15 Wright RJ, Rodriguez M, Cohen S. Review of psychosocial stress and asthma: an integrated biopsychosocial approach. Thorax 1998;53:1066-74.

16 Gibson PG, Powell H, Coughlan J, et al. Self-management education and regular practitioner review for adults with asthma (Cochrane review). In: The Cochrane Library. Issue 3. Chichester, UK: John Wiley \& Sons, 2004.

17 Fleming S, Pagliari C, Churchill R, et al. Psychotherapeutic interventions for adults with asthma (Cochrane review). In: The Cochrane Library. Issue 3. Chichester, UK: John Wiley \& Sons, 2004

18 Yoon R, McKenzie DK, Miles DA, et al. Characteristics of attenders and nonattenders at an asthma education programme. Thorax 1991;46:886-90.

19 Fitzgerald JM, Turner MO. Delivering asthma education to special high risk groups. Patient Educ Couns 1997;32(Suppl):S77-86.

20 Uldry C, Leuenberger P. Compliance, psychosocial factors and patient education in difficult or therapy-resistant asthma. Eur Respir Rev 2000;10:97-101.

21 Fitzgerald JM. Psychosocial barriers to asthma education. Chest 1994; 106:260-3s.

22 Smith JR, Mugford M, Holland R, et al. A systematic review to examine the impact of psycho-educational interventions on health outcomes and costs in adults and children with difficult asthma. Health Technol Assess 2005;9(23)

23 McAdam EK, Noble M, Harrison BDW. A combined clinic using a medical and psychological approach for the management of poorly controlled asthma. Asthma J 2000;5:71-9.

24 Mildenhall S. A home-based coping skills programme for high-risk asthma sufferers. Asthma Gen Pract 1998;6:23-4.

25 Smith JR, Mildenhall S, Noble M, et al. Clinician-assessed poor compliance identifies adults with severe asthma who are at-risk of adverse outcomes. $J$ Asthma 2005;42:437-45. 
26 Royal College of Physicians. Measuring clinical outcome in asthma: a patient focused approach. London: RCP Clinical Evaluation and Effectiveness Unit, 1999.

27 Hyland ME, Finnis S, Irvine SH. A scale for assessing quality of life in adult asthma sufferers. J Psychosom Res 1991;35:99-110.

28 Ware JE Jr, Sherbourne CD. The MOS 36-item short-form health survey (SF36). Med Care 1992;30:473-83.

29 Zigmond AS, Snaith RP. The Hospital Anxiety and Depression Scale. Acta Psychiatr Scand 1983;67:361-70.

30 Goldberg DP, Williams P. A user's guide to the General Health Questionnaire. Windsor: NFER Nelson, 1988.
31 Katz PP, Yelin EH, Eisner MD, et al. Perceived control of asthma and quality of life among adults with asthma. Ann Allergy Asthma Immunol 2002;89:251-8. 32 Morisky DE, Green LW, Levine DM. Concurrent and predictive validity of a self-reported measure of medication adherence. Med Care 1986;24:67-74

33 Oga T, Nishimura K, Tsukino $M$, et al. Comparison of the responsiveness of different disease-specific health status measures in patients with asthma. Chest 2002; 122:1228-33

34 Hays MD, Morales LS. The RAND-36 measure of health-related quality of life. Ann Med 2001;33:350-7.

35 Bland JM, Altman DG. Statistics notes: some examples of regression towards the mean. BMJ 1994;309:780.

\section{LUNG ALERT}

\section{Correlation between carbon dioxide retention during exercise and the rate of decline of $F E V_{1}$ in cystic fibrosis}

A Javadpour SM, Selvadurai $\mathrm{H}$, Wilkes $\mathrm{DL}$, et al. Does carbon dioxide retention during exercise predict a more rapid decline in $\mathrm{FEV}_{1}$ in cystic fibrosis? Arch Dis Child 2005;90:792-5.

$\mathrm{P}$ rogressive decline in lung function is an important cause of morbidity and mortality in patients with cystic fibrosis (CF). Markers to identify the patients at risk of rapid decline in their clinical condition are lacking. No study to date has used carbon dioxide $\left(\mathrm{CO}_{2}\right)$ retention during exercise to predict the rate of decline in respiratory function in CF.

In this study, the change in forced expiratory volume in 1 second $\left(\mathrm{FEV}_{1}\right)$ of $15 \mathrm{CF}$ patients who retained $\mathrm{CO}_{2}$ (measured by end tidal $\left.\mathrm{CO}_{2}\right)$ during exercise testing $\left(\mathrm{CO}_{2} \mathrm{R}\right.$ group) and 43 who did not $\left(\mathrm{CO}_{2} \mathrm{NR}\right.$ group) was compared retrospectively over a 3 year period. The two groups were matched for age and body mass index. The results showed that the $\mathrm{CO}_{2} \mathrm{R}$ group had significant declines in $\mathrm{FEV}_{1}$ at 24 months $\left(6.3 \% \mathrm{CO}_{2} \mathrm{R}\right.$ group $v 1.8 \% \mathrm{CO}_{2} \mathrm{NR}$ group, $\mathrm{p}<0.05)$ and 36 months $\left(5.3 \% \mathrm{CO}_{2} \mathrm{R}\right.$ group $v 2.5 \% \mathrm{CO}_{2} \mathrm{NR}$ group, $\left.\mathrm{p}<0.05\right)$. There was an almost 12 -fold higher risk of a fall in $\mathrm{FEV}_{1}$ of $>9 \%$ in the $\mathrm{CO}_{2} \mathrm{R}$ group over the following 3 years compared with the $\mathrm{CO}_{2} \mathrm{NR}$ group.

The authors conclude that children with $\mathrm{CF}$ who exhibit $\mathrm{CO}_{2}$ retention during exercise are at risk of a more rapid decline in lung function. However, this study is limited by the fact that $\mathrm{PaCO}_{2}$ values cannot be predicted accurately from end tidal $\mathrm{PCO}_{2}$ in an individual person, particularly in patients with lung disease affecting ventilation/perfusion relationships. It should be noted that the $\mathrm{CO}_{2} \mathrm{R}$ group had a slightly lower $\mathrm{FEV}_{1}(62.3 \%$, range $41-68 \%)$ than the $\mathrm{CO}_{2} \mathrm{NR}$ group $(64.7 \%$, range $44-69 \%)$ at the commencement of the study.

D Wat Specialist Registrar, Basildon and Thurrock University Hospitals, UK; denniswat118@hotmail.com 